\title{
La fe, instancia crítica frente a la sociedad, según san Agustín
}

En la mente de no pocos ciudadanos del Imperio Romano existía una grave prevención contra la religión cristiana. Tenían la sospecha y el temor de que la tensión escatológica, el vivir a la espera de un reino situado más allá de este mundo, habría de producir despreocupación por los objetivos e intereses de la ciudad terrena.

Por otra parte, el precepto universal del amor, la predicación de una igualdad fundamental entre todos los hombres, la existencia de una comunidad eclesial que trascendía los vínculos de identificación con la sociedad civil y que se consideraba como la expresión de la auténtica sociabilidad humana, eran factores que habrían de contribuir necesariamente a minimizar la virtud del patriotismo, el significado de las fronteras y de las diferencias naturales, y el espíritu de sacrificio por la grandeza y la gloria del Imperio.

Los contemporáneos del obispo de Hipona: no se quejaban de que los cristianos fueran poco consecuentes con las exigencias sociales y políticas de su fe, como sucede en nuestro tiempo; sino que temian las consecuencias que podrían derivarse para el orden constituido, si un día sentían la tentación de tomarlas rigurosamente en serio.

De hecho, los altos funcionarios imperiales, amigos de S. Agustín, encontraban dificultad en compaginar Evangelio y política, las exigencias del patriotismo y el precepto del amor universal. El joven Volusiano, dotado de notable inteligencia y de perspicacia política, tenía no pocas objeciones que hacer al cristianismo desde su condición de noble romano todavía fiel al paganismo. Nombrado procónsul después del 410, se estableció en Cartago y desempeñó con dedicación las altas funciones de su cargo. Permanecía pagano en medio de una familia fervientemente cristiana. Su madre Albina solicitó la ayuda de $\mathbf{S}$. Agustín para que resolviera las dudas de su hijo contra la fe cristiana y éste le escribe, ofreciéndose para resolverlas. Volusiano le plantea algunas objeciones referentes al 
misterio de la Encarnación, objeciones ya tradicionales entre los paganos, a las que S. Agustín contesta en la carta 137, donde encontramos como un esquema de la Ciudad de Dios ${ }^{1}$.

Los contactos entre S. Agustín y Volusiano fueron también favorecidos por un común amigo, el comisario Marcelino, muy interesado en intensificar las relaciones entre ambos personajes y en la conversión de Volusiano al cristianismo ${ }^{2}$. Pero los esfuerzos de la familia y de los amigos no tuvieron éxito inmediato. De hecho, Volusiano se convierte a la fe cristiana veinticinco años más tarde en la ciudad de Constantinopla y en presencia de su sobrina Melania la joven ${ }^{3}$.

Volusiano se convirtió bien pronto en el personaje central de un grupo de nobles romanos que se habian refugiado en Africa, huyendo del asedio de Roma del 410. Formaban un círculo de personas cultas, preocupadas del buen decir y de las reglas de la elocuencia, nostálgicas del pasado esplendor de Roma. Pero, al mismo tiempo, eran súbditos de emperadores cristianos y vivian en una época que había sufrido profundas transformaciones. La historia, la religión y las costumbres de la antigua Roma, que tanto admiraban, sólo podian encontrarlas en los libros. A su paganismo le faltaban raíces concretas. Era ya un fenómeno marginal en relación con el avance incontenible del cristianismo *

La caída de Roma vino a exacerbar el resentimiento de los que maldecían los tiempos cristianos en nombre de supuestos tiempos mejores del pasado. Pero, en semejante circunstancia, echaron mano de argumentos y acusaciones contra el cristianismo que tenían ya larga historia.

"Se acusa a la religión de ser enemiga de la república". Con esta frase resume $\mathbf{S}$. Agustín las objeciones de Volusiano y de su grupo en la carta 138. Marcelino le había explicado con suficiente claridad estas objeciones en la carta 136. Pero aquí interesa notar que estas objeciones de tipo socio-político contra la religión cristiana eran compartidas por funcionarios católicos del Imperio. S. Agustín escribe al comisario imperial Ceciliano, lamentándose de que un hombre como él todavía no haya recibido el bautismo. “¡Cómo si

1. Cf. V. CAPANAGA, "Intelectuales paganos del siglo V frente al misterio de Cristo. Un episodio epistolar de Agustín": Oikoumene, Studi paleocristiani publicati in onore del Concilio Vaticano II (Catane 1964) 439-454.

2. Ep. 136; cf. también A. CHASTAGNOL, "Le senateur Volusien et la conversion d'une famille de l'aristocratie au Bas-Empire": Revue des Etudes Anciennes 58 (1956) 251-252.

3. Cf. A. CHASTAGNOL, Le senateur Volusien, 253.

4. Cf. P. BROWN, Biografía de Agustin de Hipona (Madrid 1970) 351 . 
los fieles, cuando son mejores y más fleles, no pudieran administrar mejor y con mayor fidelidad la república!" 5. El célebre y desconcertante Bonifacio, que no sólo se profesaba católico sino que llegó a desear abrazar la vida monástica en una determinada etapa de su vida, también encontraba una dificultad insuperable al intentar armonizar las virtudes que se exigen a un buen ciudadano, máxime si es militar, con el Dios cristiano del amor universal, del perdón de los enemigos y de la huída de la gloria popular ${ }^{6}$.

En semejantes circunstancias era urgente mostrar que la fe cristiana no conducia a la anarquía ni tenía consecuencias nefastas para la sociedad civil. Por el contrario, contribuia a regenerarla y mejorarla. Si los reyes y todos los ciudadanos "oyeran y al mismo tiempo pusieran en práctica sus preceptos sobre las costumbres justas y santas, la república no sólo ordenaría con su felicidad las regiones de la vida presente, sino que ascenderia hasta la cumbre misma de la vida eterna" "

Es la misma transformación interior de la totalidad de la persona, operada por la gracia, la que exige lealtad a la patria y el sometimiento a los deberes que impone. El cristiano va más allá de lo que pudiera creerse posible o deseable en cuestión de responsabilidad en el cumplimiento de los deberes para con la sociedad civil. Está orientado en sus motivaciones por algo más noble que el interés o el miedo, algo que está más allá de la política y del mundo presente. Por otra parte, el cristiano participa de los bienes y ventajas de la sociedad civil y, por tanto, ha de contribuir a su defensa y a su grandeza bajo la dirección de las autoridades constituidas, excepto en el caso en que éstas ordenen algo en contra de lo dispuesto por Dios para la salvación eterna ${ }^{8}$.

En esta misma línea de pensamiento y también en reacción contra la postura de Tertuliano y de los maniqueos, S. Agustín defiende la legitimidad de la guerra, la honorabilidad de la profesión militar y hasta describe su ideal del soldado cristiano?.

Teniendo en cuenta esta preocupación por conciliar cristianismo y política, nada tendría de extraño que $\mathbf{S}$. Agustín sintiera la

5. Ep. 151, 4 .

6. Ep. 189.

7. De Civitate Dei II, 19.

8. Sobre este punto, cf. los numerosos textos agustinianos que cita e interpreta E. L. FORTIN, "L'idealisme politique d'après S. Augustin": Recherches Augustiennes 8 (1972) 250-251.

9. Ep. 189,4 ; Serm. 302, 15; Ep. 189, 7-8. 
tentación de desvirtuar la dimensión crítica del mensaje evangélico. Sin embargo, no lo hizo, porque fue un hombre que vivió en tensión escatológica hacia un reino futuro y glorioso y porque se vió obligado a defender el derecho a la existencia de la Ciudad de Dios frente a los ataques del mundo pagano. La Ciudad de Dios es una respuesta a las lamentaciones y: ataques de ciudadanos del Imperio nostálgicos del pasado, que atacaban al cristianismo en nombre de una pasada grandeza de Roma mitificada. Así se explican características de esta obra que la convierten para nosotros en un libro de gran actualidad. En ella realiza S. Agustín un trabajo decisivo de secularización y critica socio-politica en nombre de la escatología y de la trascendencia de Dios.

El obispo de Hipona tuvo una conciencia aguda de la fuerza de la esperanza para mantener al hombre en pie sobre la tierra. "No hay ninguna vida humana que esté sin esperanza y hasta en la muerte hay siempre un aliento de esperanza: esperanza en los niños para que crezcan, se instruyan y se formen en la cultura; esperanza en los adolescentes para casarse y formar una familia; esperanza en los padres para educar, alimentar y hacer hombres a los: que acariciaron cuando eran párvulos" ${ }^{10}$. Expresiones como ésta hacen pensar en la teologia de la esperanza de Moltmann y en la importancia de la utopía en la vida de los hombres, puesta de relieve por E. Bloch.

Pero el cristiano va orientado por una esperanza que le empuja más allá de este mundo y de la historia intramundana. Espera a Dios de Dios. Espera una forma nueva de existencia que no es en absoluto repetición de la que vive aquí abajo. Tan gran esperanza le hace sentirse peregrino sobre la tierra. Es cierto que la esperanza ayuda a sobrellevar con fortaleza y hasta con gozo las tribulaciones de la peregrinación. Pero está herido de nostalgia por la verdadera patria y eso hace la peregrinación amarga. Está empujado por un insaciable anhelo de unidad, de seguridad y de eternidad y siente la decepción de lo transitorio, de lo que nace y muere, de lo que dispersa en la multiplicidad y defrauda la confianza del corazón. $\mathrm{Y}$ a la virtud de la esperanza sigue la virtud del despego de las cosas terrenas con miras a las riquezas del Reino. El cristiano esperanzado tiende a despojarse de las riquezas y de si mismo para convertir su espíritu en receptáculo del Dios vivo. La grandeza mis-

10. Sermones post Maurinos reperti: Denis, Serm. 22, 2: Miscellanea Agostiniana, I (Roma 1930) 134. 
ma de su anhelo le ensancha el alma para recibir una medida colmada cuando llegue el tiempo de la visión. El pensamiento de lo eterno modera los apetitos del hombre en búsqueda afanosa de bienes terrenos. Pone medida y reposo en la acción, al mismo tiempo que le da sentido y valor ${ }^{11}$.

El hombre de la esperanza cristiana no puede evitar convertirse en escándalo y contestación viviente en medio de un mundo orientado por esperanzas intramundanas. Es testigo de realidades invisibles y que superan la capacidad de la razón en medio de gentes que sólo estiman lo sensible, lo manipulable, lo sujeto a una cierta forma de racionalidad. Son frecuentes las referencias de $\mathbf{S}$. Agustin al lenguaje mordaz con el que los paganos ridiculizaban la fe y la esperanza de los cristianos ${ }^{12}$.

La tensión escatológica y la fe en el Señor, cuya palabra crea tensiones y persecuciones en el mundo, sirven al cristiano de punto de referencia para su valoración de la realidad. De este modo se convierte en paradoja viviente, en contestatario del mundo, de su incredulidad, de sus pecados e injusticias, de su esperanza intrahistórica mitificada ${ }^{13}$.

A veces el mundo y la misma autoridad política, en un alarde de agresividad, llegan a pedir al cristiano la renuncia a su fe y a su esperanza. Pero él no puede menos de "contestar" las fuerzas humanas y las leyes que van en contra de lo dispuesto por Dios en orden a la vida eterna. Estará dispuesto a rechazar los mandatos abusivos de la autoridad civil aun a costa de la pérdida de los bienes temporales y de la misma vida. Esos bienes y esa vida quedan relativizados por el cristiano a causa de su esperanza en otra vida $\mathrm{y}$ otro reino ${ }^{14}$.

S. Agustín "permanece fiel al pensamiento escatológico en cuanto considera este mundo como un provisorium y, por ende, no intenta darle una constitución cristiana, sino que lo deja estar como mundo que ha de luchar por su propio y relativo orden. Y también su cristianismo conscientemente legal sigue siendo en cierto sentido revolucionario, por cuanto no puede plantearse como idén-

11. Sobre el tema de la esperanza cristiana en el pensamiento agustiniano, cf. V. CAPANAGA, Agustín de Hipona, Maestro de la conversión cristiana (Madrid 1974) 265-281. 261.

12. Enarrationes in Ps. 122, 8; cf. V. CAPANAGA, Agustín de Hipona, 260-

13. Enarrationes in Ps. 70, 9.

14. Exp. Prop. ex Ep. ad Rom. 72 y 74 ; Serm. 62, 9, 14; In Iohannis evangelium tr. 5, 12; Enarrationes in Ps. 104, 37; Contra Faustum XXII, 75. 
tico a ningún Estado, sino que es una fuerza que relativiza todo lo intramundano, al apuntar hacia Dios, único absoluto, y hacia el único mediador entre Dios y los hombres: Jesucristo" ${ }^{15}$.

El obispo de Hipona se coloca en una postura critica frente a la sociedad civil, cuando ésta reivindica el derecho a suprimir al ciudadano de la Ciudad de Dios, por considerarle alienado en su fe en un Dios trascendente y en su esperanza en un reino situado más allá de este mundo. Los diez primeros libros de la Ciudad de Dios obligan a los hombres y a las sociedades terrenas a dar cuenta de su fe y su culto, de sus objetivos e intereses, de sus ideales y de sus mitos. Como ha visto con perspicacia J. C. Guy, las diferentes categorías de paganismo con las que $\mathbf{S}$. Agustín mide la Ciudad de Dios están elegidas de tal forma que bajo ellas quedan subsumidas todas las formas históricas de paganismo.

La ciudad terrena se considera no alienada porque busca objetivos proporcionados a su condición humana e histórica. Defiende la religión sólo en cuanto instrumento eficaz para fines políticos intramundanos: las buenas costumbres de los ciudadanos, la prosperidad temporal y la paz. Para destruir esta pretenciosa utopía de encontrarse en la verdad y en el equilibrio, S. Agustín realiza una obra impresionante de secularización y desmitificación del Imperio romano $y$, en general, de toda sociedad civil que absolutiza objetivos intrahistóricos. Los dioses favorecieron la depravación de las costumbres en vez de la moralidad y fueron incapaces de garantizar la prosperidad temporal y de evitar continuas guerras ${ }^{16}$.

En cuanto a la historia de Roma le es fácil a S. Agustín demostrar que había sido muy distinta de la historia mitologizada en la que creía la opinión común. El orgullo colectivo y los intereses políticos expansionistas habian convertido en gloriosas hazañas del pasado acontecimientos bien poco edificantes. En la historia de Roma se glorificaba el rapto de las sabinas y otras numerosas injusticias. La Ciudad de Dios no sólo constituye un esfuerzo gigante por ahuyentar a los dioses de la historia de Roma, sino también por desmitificar esa misma historia. "¿A qué viene el alegarme el nombre de alabanza y el nombre de victoria? Removidas las sombras de la insensata opinión, considérense los hechos en su desnudez, en su desnudez pondérense y júzguense en su desnudez" ${ }^{17}$. Vistos los acon-

15. Cf. J. RATZINGER, La unidad de las naciones. Aportaciones para una teología política (Madrid 1972) 76.

16. Cf. J. C. GUY, Unité et structure logique de la "Cité de Dieu" de S. Augustin (Paris 1961) 75-76.

17. De Civitate Dei III, 14, 2. 
tecimientos en su auténtica realidad histórica y relativizados desde la perspectiva cristiana, la historia será menos portentosa, pero también más a la medida del hombre. Porque, "quita la jactancia, y todos los hombres, ¿qué son más que hombres?" ${ }^{18}$.

S. Agustín estaba convencido de la enorme influencia que la historia idealizada tiene sobre la conciencia individual y colectiva. El que individuos, familias y pueblos enteros se crean descender de dioses o herederos de memorables gestas de los antepasados, les da vigor y confianza para realizar grandes empresas ${ }^{19}$. Pero esto se consigue con detrimento de la verdad y de la religión, fomenta el orgullo individual y colectivo y contribuye a extender por el mundo el ámbito satánico de la esclavitud de la mentira. Sólo la verdad es liberadora y en este aspecto es preferible que los hombres no sean más que hombres.

Sería largo el catálogo de cuestiones a las que se extiende la obra secularizadora y desmitificadora de S. Agustín. La astrologia, los horóscopos, la brujería, numerosas tradiciones y costumbres mitificadas, merecieron de su pluma comentarios críticos llenos de ironia ${ }^{20}$. El cristiano debe sentirse tranquilo frente al mundo porque es obra de Dios y está sometido a su poder y a su providencia. En reacción contra la mentalidad estoica, que servía de base a la divinización del Imperio y de otras fuerzas en las que parecía expresarse y condensarse el alma del mundo, S. Agustín seculariza toda realidad cósmica y humana. La distinción cristiana entre creador y creatura evita dar culto a tantos dioses cuantas son las obras de las manos del Dios único ${ }^{21}$

El Imperio romano era una fuerza de tal magnitud que sólo podía ser idealizada al máximo o rechazada como energía demoniaca. Sin embargo, "Agustín juzgará el Imperio de sus méritos como una institución puramente humana; lo reducirá al nivel de cualquier Estado con objeto de expulsar a los dioses de su historia y disputará su contribución a la vida del cristiano en términos generales como para suponer que la función del Imperio podría haber sido desempeñada por cualquier otro Estado" ${ }^{22}$. No se dejó envolver en las redes del imperialismo histórico, como sucedió a muchos cristianos de su época. El Imperio es visto como una organización humana,

18. De Civitate Dei V, 17, 2.

19. De Civitate Dei III, 4

20. De Civitate Dei V, 1-7.

21. De Civitate Dei VII, 30.

22. Cf. P. BROWN, Biografía de Agustín de Hipona, 351. 
empírica, histórica, que debia estudiarse sociológicamente, considerando los valores que la animaban, para poder dar posteriormente un juicio ético o teológico desde la perspectiva cristiana. "Si el pueblo es un conjunto de seres racionales asociados por la comunidad concorde de objetos amados, para saber qué es cada pueblo, es preciso examinar los objetos de su amor" ${ }^{23}$. El juicio de valor dependerá de la calidad de los objetivos que movilizan a los miembros de la sociedad. "Cierto que (el pueblo) será tanto mejor cuanto más nobles sean los intereses que ligan a los ciudadanos y tanto peor cuanto menos nobles sean" ${ }^{24}$. De este modo queda relativizado el Imperio romano no con las leyes, instituciones y costumbres que le servían para conseguir sus fines. Era un modo humano de organizarse, semejante a los modos de organización de otras sociedades empíricas, en orden a conseguir objetivos humanos. Unas formas de organización serán mejores y más eficaces que otras, pero todas son relativas y deficientes, ya que por sí mismas son incapaces de implantar la verdadera justicia ${ }^{25}$. El orden socio-político no es salvífico en el mismo sentido en que lo es la Iglesia y los bienes de la sociedad civil no coinciden con los fines de la Ciudad de Dios. Aun en el supuesto de que la perspicacia política y la sabiduría cristiana se encuentren en el mismo individuo no llegan jamás a confundirse. En los elogios que el obispo de Hipona dedica a Constantino y Teodosio distingue con suficiente claridad entre virtudes privadas y públicas, entre motivaciones de orden cristiano y motivaciones de orden político, entre la recompensa temporal y la eterna que merecen por sus virtudes ${ }^{26}$.

El cristianismo trasciende los regímenes políticos, les deja en su condición de realidades humanas e imperfectas, exhorta a los fieles a respetar el orden relativo que encarnan, a tolerar con paciencia las consecuencias que se derivan de su imperfección constitutiva o accidental y a trabajar para mejorar y transformar la sociedad en que viven. La actitud de $\mathbf{S}$. Agustín no puede considerarse en este punto ni anárquica ni conformista.

Se ha escrito que el obispo de Hipona soñó durante algún tiempo con la regeneración posible del Imperio por medio de la religión cristiana y particularmente a través de la sabiduría y del buen ejemplo de los funcionarios que profesaban sinceramente la fe en

23. De Civitate Dei XIX, 24 .

24. De Civitate Dei XIX, 24.

25. De Civitate Dei XIX, 24.

26. Cf. E. L. PORTIN, L'idéalisme politique, 256. 
Cristo. R. A. Markus sospecha que S. Agustín se unió durante algunos años al coro de los contemporáneos para compartir su júbilo por la victoria del cristianismo. Coloca en los años 399-401 la época de mayor entusiasmo por los "tempora christiana". En sus escritos se dejaría traslucir una interpretación profética de la edad teodosiana ${ }^{27}$.

No puede negarse que S. Agustín sintió entusiasmo por la fuerza expansiva de la Iglesia, expansión favorecida por la autoridad imperial. En una carta dirigida a Nectario, noble de Calama, que pedía a S. Agustín indulgencia para con sus conciudadanos, culpables de graves daños contra la comunidad cristiana, presenta a la Iglesia extendida por toda la tierra como escuela donde se aprenden las virtudes que hacen grandes las ciudades ${ }^{28}$. Respondiendo a las objeciones de Volusiano y sus amigos, dice: "Los que dicen que la doctrina de Cristo es enemiga de la república dennos un ejército de soldados tales cuales los exige la doctrina de Cristo. Dennos tales provincias, tales maridos, tales siervos, tales reyes, tales jueces, tales recaudadores y cobradores del fisco, como los que quiere la doctrina cristiana, y atrévanse a decir que es enemiga de la república. No duden en confesar que, si se la obedeciera, prestaría un gran vigor a la república" ${ }^{29}$.

Me parece extraordinariamente significativa a este respecto la alegría que expresa reiteradamente en sus cartas a los funcionarios imperiales por la buena fama y el prestigio de que gozan ante el pueblo ${ }^{30}$. Ciertamente, S. Agustín no podía menos de pensar con alegría y entusiasmo en funcionarios imperiales cristianos como Marcelino, el futuro mártir, su amigo entrañable. Era un hombre educado, culto, ferviente cristiano, preocupado de cuestiones filosóficas y teológicas, que se esforzaba por cumplir las funciones propias de su cargo con espíritu de justicia y de clemencia. La pena y la indignación que siente el obispo de Hipona, cuando su amigo Marcelino es acusado de complot contra el Estado y condenado a muerte, expresan bien a las claras el afecto y la admiración que le profesaba. La semblanza que trazó de su amigo y confidente después de su ejecución está llena de admiración por sus cualidades y virtudes: “¡Cuánta honradez en sus costumbres, fidelidad en la

27. Cf. R. A. MARKUS, Saeculum: History and Society in the Theology of S. Augustine (Cambridge 1970) 31-36.

28. Ep. 91, 4; De Civitate Dei XVIII, 41.

29. Ep. 138, 2, 15.

30. Ep. $112 ; E p .189,8$. 
amistad, afán en la doctrina, sinceridad en la religión, pureza en el matrimonio, continencia en el juicio, paciencia para con los enemigos, afabilidad para con los amigos, humildad para con los santos, caridad para con todos, facilidad para otorgar beneficios, pudor para pedirlos, amor para las buenas acciones, dolor para las malas!" ${ }^{31}$.

Los funcionarios imperiales cultos fueron para la inteligencia de S. Agustín un estimulo eficaz y constante. Sabian apreciar sus obras y contribuían a propagarlas. Muchos de los problemas difíciles a cuya investigación dedicó el obispo de Hipona los mejores esfuerzos de su inteligencia le fueron planteados por funcionarios imperiales. El les recompensaba con una sincera admiración por la competencia y espíritu de sacrificio de que daban muestras en la administración de la cosa pública. La admiración terminaba en verdadera y profunda amistad, especialmente cuando los veía interesados en la vida cristiana.

Pero las frases agustinianas de entusiasmo acerca de los tiempos cristianos, de la sorprendente extensión de la Iglesia por el mundo, actuando como escuela de virtudes cívicas, de los funcionarios cristianos que parecian emular las cualidades de los antiguos romanos, no constituyen una prueba concluyente en favor de una sacralización cristiana del Imperio. Aunque S. Agustín estuviera convencido de la relatividad y secularidad de todos los proyectos exclusivamente humanos, no podía negar la irrupción de lo divino en la historia, especialmente en el pueblo de Israel y en la Iglesia.

La progresiva y sorprendente cristianización del Imperio, la prohibición del culto pagano, los milagros numerosos que tenian lugar en las tumbas de los mártires, las transformaciones espectaculares operadas por la gracia en el interior de las almas, el mismo fenómeno de la vida eremítica y cenobítica, todos estos hechos eran demasiado sorprendentes y no podían explicarse fácilmente sin admitir que se estaba realizando una historia sagrada en medio de la historia secular. Sin embargo, las dos historias se diferencian en su origen, en sus métodos, en sus motivaciones y en sus objetivos. Los acontecimientos a que da lugar la búsqueda de prosperidad terrena y de un orden encaminado al equilibrio de intereses son de naturaleza distinta a los que realiza la acción misteriosa y gratuita de Dios en la historia. Es perfectamente posible una interpretación profética de la destrucción de los ídolos y de la masiva conversión

31. Ep. 151, 8. 
de las gentes del Imperio al cristianismo, sin necesidad de recurrir a la sacralización del mismo.

Por extraño que parezca, y a pesar de haber sido acusado de legitimador teórico del viraje constantiniano, S. Agustín no puede de ser considerado ni siquiera como sacralizador de la misma Iglesia. Esta es, ciertamente, forma visible de la Ciudad de Dios en la historia y testigo del ámbito de la santidad en medio del mundo. Pero todo eso lo es la Iglesia en virtud de la fuerza que le viene de lo alto y de su dimensión escatológica. En cuanto sociedad visible y empírica es un corpus permixtum, en el que no son visibles las fronteras entre los ciudadanos buenos y los falsos. Ya desde su polémica contra los donatistas, S. Agustín se alejó claramente de la corriente teológica africana que tendía a identificar la Iglesia histórica, sociológicamente observable, con los santos de la Ciudad de Dios ${ }^{32}$.

Concebir la Iglesia como una sociedad en la que es imposible distinguir con claridad entre miembros verdaderos y falsos, evita la mitificación de toda comunidad cristiana empírica. En los mismos monasterios, centros de convivencia de aquellos fieles que deseaban ser perfectos cristianos dentro de la Iglesia, se encuentran buenos y malos. S. Agustín lo reconocerá lealmente y alguna vez tuvo la oportunidad de comprobarlo por experiencia en los que había fundado. $Y$ aunque siempre estuvo preocupado de la buena fama hacia el exterior de sus comunidades monásticas, no le gustaba que se hiciera de ellas un mito a base de alabanzas excesivas. Toda comunidad cristiana ha de reconocer con humildad sus defectos y la necesidad permanente de reformarse y mejorarse.

La Iglesia es santa en cuanto participa de Cristo y de los medios de salvación que le otorgó. Sin embargo, en la conciencia de sus miembros concretos, la santidad es un ideal a alcanzar, una tarea de tensión y de lucha que sólo acaba después de nuestra peregrinación por este mundo. Semejante concepción de la Iglesia le fue facilitada a $\mathbf{S}$. Agustín por el pensamiento neoplatónico, que consideraba la realidad en constante devenir hacia las formas ideales del mundo inteligible, reflejándolas de manera imperfecta y jerárquica. También se ha hecho notar la influencia de Ticonio, creador de una teología de la santidad de la Iglesia desde la perspectiva escatológica ${ }^{33}$.

Si esto pensaba de la Iglesia, su entusiasmo no podía ser muy grande respecto a las posibilidades de la sociedad civil. Las frases

32. Cf. R. A. MARKUS, Saeculum: History and Society, 114-124.

33. Cf. R. A. MARKUS, Saeculum: History and Society, 117. 
en las que ensalza al Imperio cristiano, a la Iglesia en cuanto escuela de ciudadanía, a los funcionarios austeros y patriotas que podía y debía suscitar una doctrina que predicaba la honradez y el amor fraternal, deben entenderse en el contexto de una difícil polémica contra los que veían el cristianismo como enemigo del Estado. No es menester esperar al desgraciado incidente del proceso y posterior ejecución de Marcelino, al que no pudo salvar la influencia de la Iglesia puesta en juego, ni a los graves pensamientos de S. Agustín en torno al misterio de la elección y predestinación de los hombres y de los pueblos por parte de Dios en la polémica antipelagiana, para encontrar en sus escritos una relativización de la alianza entre la Iglesia y el Imperio y una constatación realista de la tendencia de las masas cristianas a dejarse conducir por los atractivos del mundo y por hábitos inveterados. Desde su época de sacerdote hubo de aprender por propia experiencia la dificultad y la lentitud con que se consiguen reformar las costumbres de una comunidad y la situación precaria en que las reformas se mantienen. En cuanto a las posibilidades de la acción política, no basta acentuar las ventajas que ve S. Agustín para la unidad de la Iglesia en la intervención de los poderes públicos en la controversia donatista, asi como tampoco es suficiente fijarse en las expresiones en las que muestra un acentuado desinterés por la política, especialmente en la carta 220 dirigida a Bonifacio después de sus desconcertantes y desastrosas acciones contra el Imperio ${ }^{34}$. El pensamiento agustiniano acerca de la intervención del poder civil no sólo cambió bajo la presión de las circunstancias, sino que en todo momento consideró los medios exteriores que le son propios como imperfectos e inadecuados para conseguir la conversión y transformación de las conciencias ${ }^{35}$. Lo que parece seguro, como explica $R$. A. Markus, es que en el pensamiento agustiniano la justificación de la intervención política en materia religiosa no deriva de una Reichstheologie, sino más bien de una estrategia o severidad pastoral ${ }^{36}$. Mandouze, por su parte, opina que S. Agustín cae en error en este punto en la medida en que creyó de buena fe en el valor universal del esquema bíblico del "temor como principio de la sabiduría" y en la medida en que su falta de experiencia política le ocultó el carácter mixtificador de una fuerza que sólo se pretendía mostrar con la sana intención de no tener necesidad de servirse de

34. $E p .220,2,5$.

35. Cf. S. COTTA, La città politica di Sant'Agostino (Milano 1960) 112.

36. Cf. R. A. MARKUS, Saeculum: History and Society, 148-149. 
ella ${ }^{37}$. En todo caso, S. Agustín no es un hombre inclinado a la mitificación de la acción política, aunque ésta sea ejercida por funcionarios cristianos y en favor de la misma Iglesia.

Otra cuestión distinta es preguntarse hasta qué punto creyó $\mathbf{S}$. Agustín en una posible regeneración del Imperio y de cualquier sociedad mediante el influjo de la Iglesia, que puede transformar desde dentro los corazones con su doctrina y los medios de santificación de que dispone. A este respecto es sintomático que en casi todos los textos en que pone de relieve la armonía entre religión cristiana y política y las ventajas que se derivan de las virtudes que predica la Iglesia para la sociedad civil, usa expresiones condicionales. Un texto de la Ciudad de Dios es extraordinariamente claro sobre este punto. Después de afirmar que la república sería feliz en esta vida y estaria destinada a la felicidad eterna, si todos los ciudadanos cumplieran los preceptos de la religión cristiana, continúa: "Pero porque éste oye y aquél desprecia, y la mayoría son más amantes del halago de los vicios que de la útil aspereza de las virtudes, a los siervos de Dios, ora sean reyes o príncipes, ricos o pobres, libres o esclavos, de cualquier sexo, se les manda que toleren, si fuera necesario, a esa república aún pésima y disolutísima" ${ }^{38}$. Agustín era un hombre suficientemente lúcido y realista para constatar que los principios cristianos apenas habían calado en el corazón de numerosos fieles y que en otros eran fácilmente vencidos por las sugestiones del orgullo, de la vanagloria, del ansia de poder y de riquezas. Una sociedad de santos sobre la tierra, dirigidos en todo momento por una fe vida y actuante, apenas podía esperarse ni siquiera de las comunidades monásticas. Pero esta constatación empírica nunca logró apagar su convicción teórica de que la fe cristiana, si fuera profesada sinceramente y en su integridad, conduciría a la reforma de las costumbres de los ciudadanos, a una convivencia armoniosa, y a la implantación de una justicia conveniente.

La Ciudad de Dios no se contenta con demostrar la alienación que sufre la ciudad terrena y con señalar sus ídolos, sino que vá más allá e intenta hacer reconocer a los paganos que el cristianismo es el cumplimiento y la superación de sus aspiraciones más profundas y el único camino de liberación integral y total ${ }^{39}$. Para $\mathbf{S}$. Agustín no hay camino de liberación fuera de Cristo. "Esta es la re-

37. Cf. A. MANDOUZE, Saint Augustin. L'aventure de la raison et de la grâce (Paris 1968) 385.

38. De Civitate Dei II, 19.

39. Cf. J. C. GUY, Unité et structure, 75-76. 
ligión que contiene el camino universal para la salvación del alma" ". Es la senda de liberación "concedida a todas las gentes", la que "purifica al hombre entero y prepara al mortal para la inmortalidad de todas sus partes constitutivas" ${ }^{41}$.

El cristiano aspira a conquistar el espíritu de libertad y la libertad de la caridad, que abren ante su mirada horizontes nuevos y dilatados, enriquecen su dinamismo interior y le conducen a obrar por amor al mismo bien. En la mentalidad agustiniana el acto libre por excelencia es el acto de caridad. En él resplandece la gratuidad y la espontaneidad. "En el bien obrar no hay vínculo de necesidad, porque reina la libertad de la caridad" 42.

La gracia no es destrucción del libre albedrio, sino su liberación. No es un régimen arbitrario de acciones divinas determinantes sino amor, adhesión personal espontánea, atracción y delectación. Es revelación del alma de la amabilidad divina, alcanzándola en su intimidad y atrayéndola por la fe, que se expansiona en caridad. Es el crecimiento de la caridad en el alma el que libera, progresivamente y no sin combate mientras dura la peregrinación, de todo aquello que mantiene al hombre encerrado en el amor exclusivo de sí, en el orgullo y en la sensualidad. Liberación que sólo se-

rá completa y definitiva en la vida del más allá ${ }^{43}$.

Pero la liberación cristiana no sólo afecta a los individuos. Tiene también honda repercusión en la vida de las colectividades. Porque éstas tienden a la mitificación de valores intramundanos, a sacralizar normas y costumbres que se juzgan indispensables para la existencia o la prosperidad del grupo. Como ya se ha hecho notar, el ejemplo más espectacular de semejante proceso de mitificación lo encontró S. Agustín en el Imperio Romano, cuya absolutización condujo a instrumentalizar la religión $\mathrm{y}$ a mitificar tradiciones $\mathrm{y}$ costumbres que se juzgaban provechosas para su mantenimiento o expansión. "Según la concepción cristiana, en cambio, no se trata de la costumbre sino de la verdad, la cual no está en modo alguno organizada por el Estado, sino que es ella misma quien ha organizado una nueva comunidad que alcanza a todos cuantos viven de la verdad de Dios. $\mathrm{Y}$ partiendo de aquí entiende Agustín como libera-

40. De Civitate Dei $\mathrm{x}, 32,1$.

41. De Civitate Dei $\mathrm{X}, 32,2$.

42. De natura et gratia 65,78 .

43. Cf. J. BONNEFOY, "L'idée augustinienne du chrétien": Recherches $A u$ gustiniennes 5 (1968) 51-53. 
ción la fe cristiana: liberación para la verdad de la constricción de la costumbre" 4 .

El ansia de sobrevivir y sobresalir, de conservar y ampliar lo conquistado, tanto en los individuos como en las colectividades, conducen los espiritus al enquistamiento y a la agresividad. $Y$ también a la deificación del Estado, de la polis, de la raza, de la clase social, del partido, creando instituciones, normas y usos que contribuyen a extender entre los hombre el ámbito satánico de la esclavitud. En el pensamiento agustiniano la trascendencia y la escatología cristianas liberan de la tendencia a mitificar realidades intramundanas, relativizándolas, y la caridad saca a los hombres y a los grupos de su enquistamiento y de la tendencia egoísta a replegarse sobre sí mismos.

Ratzinger ha sabido resumir con precisión este aspecto liberador de la fe cristiana tal como lo entiende S. Agustín. "El avasallamiento del hombre a costumbres contrarias a la verdad entregan a éste a fuerzas impias, llamadas demonios por la fe cristiana... Ahí radica el verdadero calado de la liberación cristiana y de la libertad ganada merced a ella. Al liberar de la costumbre, libera de una fuerza creada ciertamente por el hombre, pero que, hace ya mucho, había resaltado por encima de su cabeza y ahora le enseñorea. Se ha convertido en una fuerza objetiva, independiente de él; en puerta de invasión de los poderes del Malo, es decir, de los demonios. Liberarse de la costumbre para ir a la verdad, es liberación del poder de los demonios, que están tras la costumbre. El sacrificio de Cristo y de los cristianos se hace verdaderamente comprensible como redención, es decir, como liberación, por su abolición del culto político (contrario a la verdad, culto demoniaco) y porque en su lugar instaura el culto uno y universal a la verdad, que es culto a la libertad" 45 .

Lo preocupante de los principados y potestades, que flotan como en el aire y se extienden por el mundo, radica en que impiden al hombre el acceso a la trascendencia y le envuelven en una atmósfera de valores relativos y esclavizantes, por hallarse mitificados. $\mathbf{S}$. Agustín no hubiera visto con buenos ojos la contribución de algunos teólogos modernos a la mitificación del progreso, de la sociedad opulenta, de la civilización urbana, de la política y de la revolución. Las esperanzas intrahistóricas, a nivel utópico, son terriblemente

44. Cf. J. RATZINGER, La unidad de las naciones, 55.

45. Cf. J. RATZINGER, La unidad de las naciones, 70-71. 
peligrosas y llevan dentro gérmenes de esclavitud. La ciencia, el progreso, la sociedad opulenta, la raza, la inmaculada concepción del proletariado, el partido, el sexo, las posibilidades de las técnicas de ingeniería social, éstos y otros valores absolutizados han exigido tanto sacrificio, fe y devoción a sus adeptos como la divinidad más exigente. Desde este punto de vista, se comprende la necesidad de una continuación de La Ciudad de Dios, adaptada a nuestro tiempo, de la que hablara hace ya años Maritain ${ }^{46}$. Tal continuación no deberá contentarse con la simple constatación de la existencia de los numerosos idolos y mitos que segrega la sociedad industrial, como han hecho ya Alfred Sauvy, Raland Barthes y otros, sino que deberá examinarlos y criticarlos a la luz de una fe vigorosa y de una esperanza viva. He aquí una tarea apasionante para los que se sientan herederos del espíritu de $\mathbf{S}$. Agustín. La teología de la esperanza de J. Moltmann y la teología política de J. B. Metz han intentado algo semejante en nuestro tiempo.

Hacer efectiva en las conciencias esta liberación cristiana no es tarea fácil ni se consigue sin renuncia y ascesis. S. Agustín recuerda con frecuencia que el mundo mete demasiado ruido a nuestras espaldas y tiene gran capacidad de seducción. Es muy difícil superar la presión de la supersticiosa credulidad popular de la opinión. No debe olvidarse que el héroe cristiano por excelencia es el mártir, "que no se ha dirigido según las potestades, según la opinión general, según el ello, sino que las ha superado por su fe en el mayor poderio de Dios. Su victoria es el sufrimiento, el decir no a las potestades que determinan al público. Agustín considera el martirio como la forma especial de triunfo de la victoria cristiana en este tiempo y ve en el mártir la señal de la Iglesia".

La actitud de Varrón y de otros intelectuales paganos, que ridiculizaban el paganismo, al mismo tiempo que lo justificaban como religión popular, daba mucho que pensar a S. Agustín. Era una prueba elocuente de la fuerza arrolladora sobre las conciencias de la supersticiosa credulidad popular y de la costumbre. Para superarlas, no era suficiente la lucidez intelectual. Eran necesarias la revelación cristiana y la gracia. Sólo la fe en un Dios único y trascendente al mundo puede liberar de la tendencia a ver condensadas fuerzas divinas en las realidades del mundo. Sólo la esperanza en una forma de existencia, que no será repetición de la que vivimos

46. Cf. J. MARITAIN, De la sagesse augustinienne: Distinguer pour unir ou les degrés du savoir (Paris 1934) 609. 
en la tierra, podrá liberar del excesivo apego a los bienes de la tierra y de la tendencia a considerarlos como bienes últimos. Sólo la gracia puede dar fuerza para superar la presión de la opinión popular, de las costumbres, usos e instituciones que, una vez que han sufrido el proceso de mitificación, se convierten en fuerzas opresoras que extienden entre los hombres el ámbito satánico de la esclavitud.

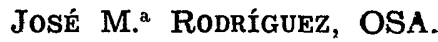
Universidad Pontificia

SALAMANCA 